\title{
Comparison of Results from Experimental Testing of Three Variants of Turbine Stage with Modern 3D Blades
}

\author{
P. Milcak ${ }^{1}$, P. Zitek ${ }^{1}$ and M. Hoznedl ${ }^{2}$ \\ ${ }^{1}$ Department of Power System Engineering, University of West Bohemia, Univerzitni 22, 30614 Pilsen, CZ \\ ${ }^{2}$ Experimental Research, R\&D department, SKODA POWER, Tylova 1/57, 30128 Pilsen, CZ
}

\begin{abstract}
Recent design of steam turbine stages is based on the use of 3D blades. This paper presents a comparison of experimental results from testing of three variants of this modern bladings with moderate hub reaction. The influence of row density of nozzles was investigated. Comparisons of overall stage efficiency as well as measured flow fields data are presented in the paper.
\end{abstract}

\section{Introduction}

The efficiency estimation of bladings is one of the key issues in the turbine flow path design. Methodology and rules of the efficiency prediction belong to the most valuable and the most classified know-how of steam turbines producers. It is built not only in the R\&D departments but also is usually based on long-term experiences from the real operation. The improvement of the CFD calculations in recent years allows to successfully and more trustworthy simulate the influence of many geometrical and operational factors. However the experimental testing, both laboratory and in real operation, still holds their important role.

This paper deals with the experimental testing of a turbine stage with 3D nozzles and buckets. General aim of the shaping is the reduction of secondary losses [4]. A scaled HP stage has been tested on a single-stage air turbine. The research has been conducted in the laboratory of the Department of Power System Engineering at the University of West Bohemia in Pilsen under the long-term cooperation with the SKODA POWER company.

The tested stage is labelled as "Full3D" because of advanced shaping of both stator and rotor blades rows. The first tested stage variant had the relative width of nozzles $\mathrm{t} / \mathrm{B}_{\mathrm{ax}}=0.61$ (co called high-density row). The second variant had changed blade number and relative width to $\mathrm{t} / \mathrm{B}_{\mathrm{ax}}=1.12$ (low-density row). The recently tested case has nozzle $\mathrm{t} / \mathrm{B}_{\mathrm{ax}}=0.92$ (middle-density row). All cases had the same bucket blades, the changes were made only on nozzles (different row density and shapes).

This paper gives results of measurement of stage efficiency and flow fields measurements behind stator and rotor blades. A five-hole probe was employed for these measurements. Data comparison of the three stage cases is presented and also comparison with the reference stage case with prismatic blades is done.

\section{Experimental rig}

All the testing was done on a single-stage air turbine (figure 1) in the laboratory of the Department of Power System Engineering, University of West Bohemia in Pilsen. Inlet and outlet stage pressures and temperatures, turbine revolutions and torque are measured to calculate the stage power and efficiency. The rig is equipped with a traversing device which allows detailed measurements of flow fields behind stator and rotor blades. A five-hole probe is used for the flow field measurement; losses of nozzle and bucket row can be evaluated separately.

The stage efficiency obtained by five-hole probe measurement is in a very good agreement with the efficiency stated from torque. Relative error of the efficiency measurement was calculated as $0.67 \%$. Detailed information about measurement and evaluation process and error estimation is given in [5].
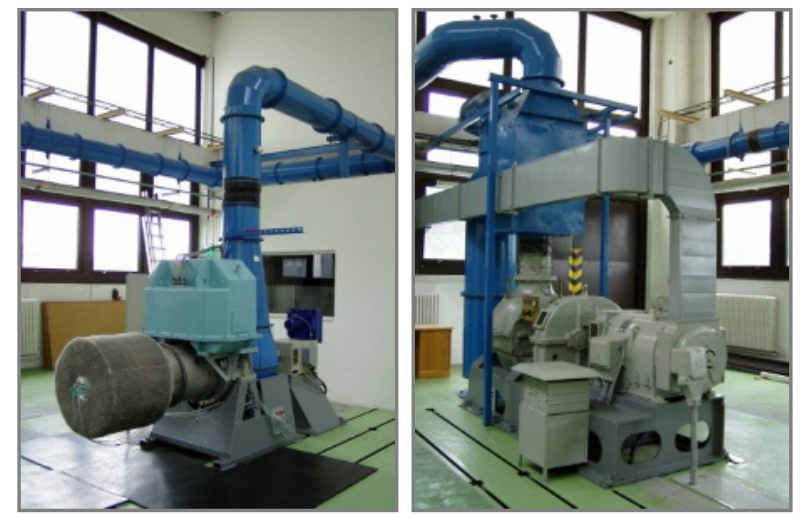

Fig. 1. Photo of the experimental rig 


\section{Three tested cases}

The design of blades was done in the R\&D department of SKODA POWER and is based on the modern design of 3D bladings dedicated for HP and IP steam turbines. The basic geometrical data are in table. 1. All cases of nozzles use the same $3 \mathrm{D}$ features. A Compound Lean principle is applied to weaken the secondary flow vortices resulting in reduction of endwall losses. It is combined with Controlled Flow for redistribution (control) the mass flow along the blade length; where the blade channel near endwalls is closed and the midspan region is opened. Practically it means that different cross section profiles are used in hub, midspan and tip.

Table 1. Basic geometrical data

\begin{tabular}{|c|c|c|c|}
\hline & \multicolumn{3}{|c|}{ NOZZLE BLADES } \\
\hline case & variant 1 & variant 2 & variant 3 \\
\hline $\mathrm{D}_{\mathrm{h}}[\mathrm{mm}]$ & \multicolumn{3}{|c|}{400} \\
\hline $\mathrm{L}[\mathrm{mm}]$ & \multicolumn{3}{|c|}{44.5} \\
\hline $\mathrm{N}$ [1] & 42 & 21 & 28 \\
\hline $\mathrm{t} / \mathrm{B}_{\mathrm{ax}}[1]$ & 0.61 & 1.12 & 0.92 \\
\hline & \multicolumn{3}{|c|}{ BUCKET BLADES } \\
\hline $\mathrm{D}_{\mathrm{h}}[\mathrm{mm}]$ & & 400 & \\
\hline $\mathrm{L}[\mathrm{mm}]$ & & 47 & \\
\hline $\mathrm{N}$ [1] & & 56 & \\
\hline $\mathrm{t} / \mathrm{B}_{\mathrm{ax}}[1]$ & & 0.75 & \\
\hline
\end{tabular}

The buckets were used the same for all three tested nozzle cases. They are designed to set an increased (about $15 \%$ ) stage reaction in the hub (moderate hub reaction stage). This means a slight close of the channel to increase the acceleration of the flow (and reaction as well) - the purpose is the additional loss reduction. The modification of the leading edge is the essential feature of the bucket 3D shaping. The shape is adjusted by cross profile turning and partial modification to adapt the outlet flow field from nozzles with controlled flow. Therefore this stage is designated as „Full3D” (for more see [3]).

\section{Results}

The employed testing procedure was developed and successfully verified in previous experimental work (see references) hence was used without any changes. The efficiency (and other parameters) was firstly measured as a function of velocity ratio $u / c$. After that the flow field measurement behind stator and than behind rotor at the optimal working mode, i.e. operation with the highest efficiency, was done. Acquired data were also compared with data from stage of original prismatic design (prismatic both nozzles and also buckets blades).

\subsection{Stage efficiency}

The stage efficiency was stated based on torque measurement at constant 2300 RPM. The velocity ratio $u / c$ has been adjusted by changing the stage pressure drop. That was set by the blower power to reach a range about 2500-7000 Pa. For this pressure drop we got the velocity ratio range of $\mathrm{u} / \mathrm{c} \sim 0.41-0.73$. The results of this measurement are in figure 2 .

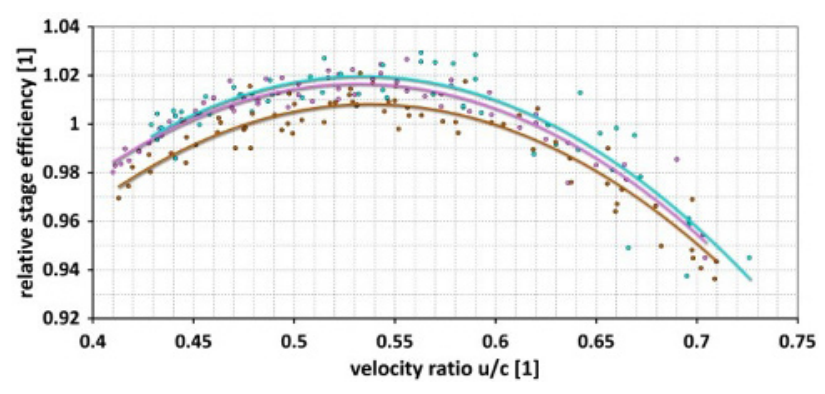

Fig. 2. Relative stage efficiency as a function of hub velocity ratio $u / c$

The efficiency here is shown as a ratio to the highest efficiency of the reference (Prismatic) bladings. Optimal hub velocity ratio for all Full3D cases is approximately the same 0.53 (pressure drop about $4300 \mathrm{~Pa}$ ). The comparison of the optimal operation mode data for Full3D bladings and reference Prismatic bladings is in table 2 . The variant 1 and 2 have practically the same efficiency; the efficiency of the third variant is lower about $0.9 \%$. However all the Full3D stages are better than the reference stage with prismatic blades.

Table 2. Efficiency and optimal velocity ratio comparison

\begin{tabular}{|l|c|c|c|c|}
\hline case & Prismatic & Full3Dv1 & Full3Dv2 & Full3Dv3 \\
\hline$\eta / \eta_{p r i s m}$ & 1 & 1.0173 & 1.0185 & 1.0081 \\
\hline$(u / c)_{h u b}$ & 0.490 & 0.530 & 0.535 & 0.535 \\
\hline
\end{tabular}

\subsection{Flow fields measurement}

Five-hole probe measurement was done at the optimal regime in the plane $11 \mathrm{~mm}$ downstream the nozzles trailing edges, respectively $10 \mathrm{~mm}$ behind the buckets trailing edges. The pitchwise stage reaction distribution is presented in figure 3 . Both variant 1 and 2 have practically the same reaction distribution (only a small deviation in the hub region is present). The third case differs little more. A reaction drop about $2-3 \%$ is present almost along whole blade length. This drop is most likely connected with the nozzle outlet angle reduction that was found out during the measurement (not presented here). 
The relative mass flow distribution is depicted in figure 3. A strong effect of Controlled Flow was observed in the variant $2-$ low-density row. The first and the third case behaviour is almost the same; only slight difference is observed in the upper part of the channel.

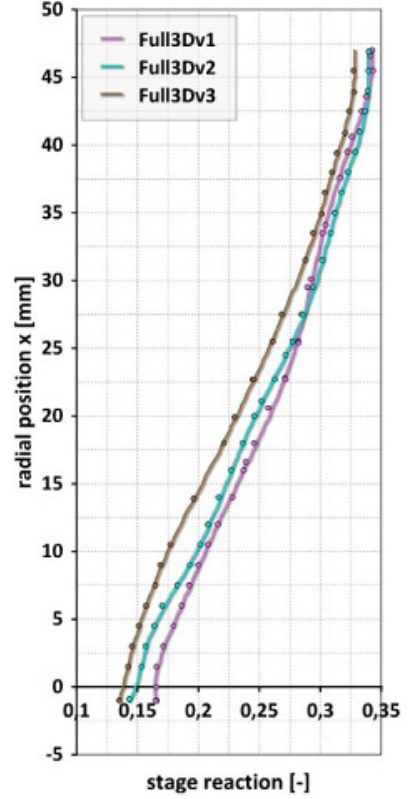

Fig. 3. Stage reaction

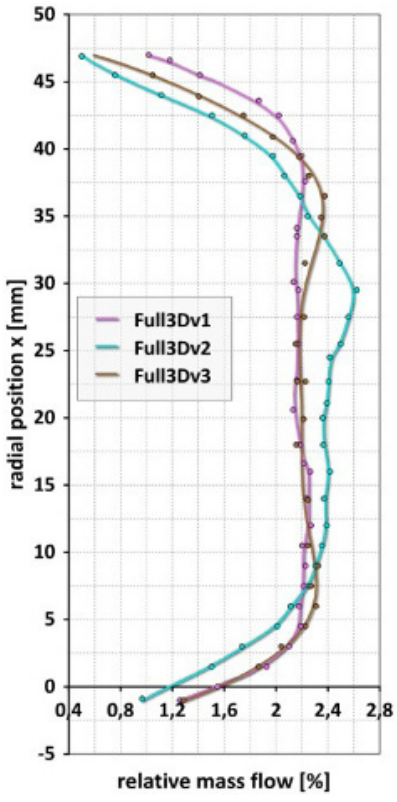

Fig. 4. Relative mass flow
It is important to mention, that the use of Controlled Flow feature at all three variants significantly reduced the flow near the endwalls and increased it in the midspan compared to the Prismatic case. However the benefit from this was not as big in the nozzle losses as in the bucket losses. This will be shown later on and was already discussed in [1] and [2].

The next two charts (figure 5 and 6) show the pichwisely mass averaged loss coefficient of stator and rotor blades. The whole stage loss coefficient is in figure 7 .
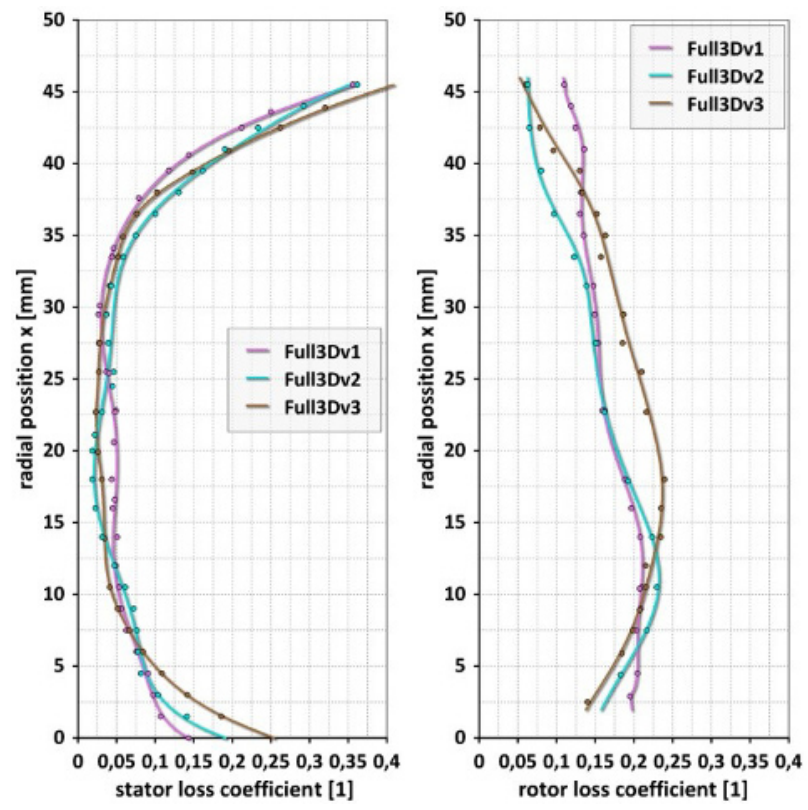

Fig. 5. Stator loss coefficient Fig. 6. Rotor loss coefficient
The stator losses in the case of variant 1 were substantially reduced in the endwall regions and slightly increased in the midspan. However the overall result (see table 3) was best from all tested cases. The figure 5 also clearly shows de facto opposite effects for variant 3 - loss reduction in the midspan part of the channel and increase near its endwalls. Nevertheless these differences (see relative efficiency in table 3 ) are very small and in the overall stage performance play just a minor role.

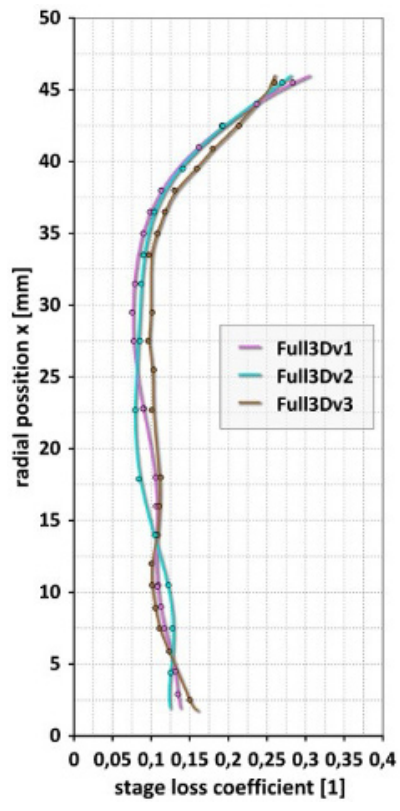

Fig. 7. Stage loss coefficient

The differences in rotor loss coefficient (figure 6) among the tested cases are much higher. Mainly the increase for variant 3 in the midspan is obvious as well as the difference near the endwall for variant 1 and 2. All these are likely related with the mass flow distribution and also number (and power) of wakes coming from nozzles.

Table 3. Comparison of averaged relative efficiencies

\begin{tabular}{|c|c|c|c|c|c|}
\hline & case & Prismatic & Full3Dv1 & Full3Dv2 & Full3Dv3 \\
\hline \multirow{3}{*}{ 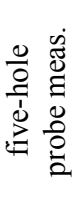 } & stator & 1.0580 & 1.0621 & 1.0541 & 1.0526 \\
\hline & rotor & 0.9281 & 0.9619 & 0.9762 & 0.9491 \\
\hline & stage & 0.9972 & 1.0173 & 1.0183 & 1.0066 \\
\hline 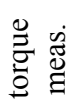 & stage & 1.0000 & 1.0173 & 1.0185 & 1.0081 \\
\hline
\end{tabular}

Overall stage losses obtained by five-hole probe measurement are plotted in figure 7 as pitchwise mass averaged values for all three Full3D cases. The differences are not significant. Variants 1 and 2 are practically the same; variant 3 has higher losses in the upper part of the channel. 
The data presented above were spanwisely averaged and are presented as relative efficiencies (to the Prismatic stage efficiency) in the table 3 . It is important to note, that the stage losses from flow field measurement, respectively efficiency, are in a very good agreement with the values obtained by torque measurement.

\section{Conclusions}

Paper presents new results of ongoing research focused on the influence of 3D shaping of steam turbine blades. The attention is dedicated to the influence of nozzle row density. Three stage cases were tested - Full3Dv1 (highdensity row), Full3Dv2 (low-density row) and recently Full3Dv3 (middle-density row).

Only very small difference was found in the overall stage efficiency between Full3Dv1 and Full3Dv2 (the second one was negligibly better). The third case stage efficiency is about $0.9 \%$ lower than previous cases. This is probably due to the unwanted change in the stator outlet flow angle that caused a slight change in reaction and also rotor incidence (not presented here). Nevertheless all the Full3D stages performance was better than the reference stage with prismatic blades. This proves that it is necessary to consider the stage as a unit and not separately stator and rotor blades. This idea was broadly discussed in [5].

A strong influence was observed on the mass flow redistribution at the variant 2 despite the fact, that the bladings shaping (Controlled Flow and Compound Lean) was based on the same principle. This is probably connected with the row density and means a good motive for further study.

The decision about the use of low-, middle- or highdensity row is managed by stress requirements together with the requirements on specific blade number ratio (blade dynamics). In the design of HP and IP turbines the high-density row is used for couple of first stages. The low-density row is dedicated primarily for end part of the flow path. Middle density row is usually present in the central part. This experimental testing showed that there are just minor differences in the performance of all three stage cases and can be mutually substituted according to the above mentioned requirements.

\section{References}

1. P. Milcak, M. Hoznedl, P. Zitek, Exp. Fluid Mech., (2011), DOI: 10.1051/epjconf/20122501054

2. P. Milcak, M. Hoznedl, Exp. Fluid Mech., 417-422, (2010), ISBN 978-80-7372-670-6

3. Milčák, P., M. Hoznedl, D. Krivánka, Strojárstvo, Mech. Eng. Jour., 180-182, (2009), ISSN 1335-2938.

4. P. MILCAK, Acta Avionica, (October, 2008), ISSN 1335-9479.

5. P. Milčák, Experimentální výzkum vlivu prostorového tvarování lopatek na proudění a ztráty $\mathrm{v}$ turbínových stupních. dizertační práce $(\mathrm{PhD}$ theses), ZČU v Plzni, (2010).

\section{Acknowledgement}

Presented research works have been supported by student grant SGS-2012-072 (Zvyšování účinnosti, spolehlivosti a životnosti energetických strojů a zařízení 2) and project CZ.1.05/2.1.00/03.0108 (Sustainable Energy, SUSEN. 